\title{
Neurokinin 1 Receptor Antagonists for Pruritus
}

\author{
Majid Alam ${ }^{1,2,3} \cdot$ Joerg Buddenkotte ${ }^{1,2,3}\left(\right.$ ID $\cdot$ Fareed Ahmad $^{1,2,3} \cdot$ Martin Steinhoff $^{1,2,3,4,5,6}$
}

Accepted: 6 February 2021 / Published online: 6 March 2021

(c) The Author(s) 2021

\begin{abstract}
Pruritus, commonly known as itch, is a very common symptom in numerous dermatological disorders and systemic diseases. It can manifest as acute, or when lasting longer than 6 weeks, it is considered chronic and can lead to significant distress and reduced quality-of-life of those suffering. Current therapeutics are limited and are lacking in efficacy, and the development of more effective treatments is needed. The neurokinin 1 receptor (NK1R) antagonists are a novel class of drugs that possess several properties such as antidepressant, anxiolytic and antiemetic activities. Recently, several studies have described the antipruritic activity of NK1R antagonists for treating chronic pruritus. In this review we outline the pathogenesis of chronic pruritus, the mechanism by which the neuropeptide substance P (SP) and its receptor NK1R may be targeted to inhibit pruritic activity, and the efficacy and tolerability of NK1R antagonists, which have been, or are currently being investigated for treating conditions where chronic pruritus is a major symptom. Increasing evidence from ongoing and completed studies demonstrates the importance of SP and NK1R signalling in mediating pruritic activity. Several NK1R antagonists have shown significant antipruritic activity and thus targeting the SP-NK1R pathway may provide a therapeutic option for treating chronic pruritus of certain origin/s in the foreseeable future.
\end{abstract}

\section{Introduction}

Pruritus, commonly known as itch, is a common somatosensory experience defined as an 'unpleasant sensation which triggers desire or urge to scratch' [1]. It is normally benign and when short lasting is considered acute; however, when lasting more than 6 weeks is defined as chronic, and can lead to a significant reduction in patient's quality-of-life $(\mathrm{QoL})$ $[2,3]$. Although pruritus is the one of the most common hallmarks of numerous skin inflammatory disorders, knowledge on the underlying pathways and mechanisms of the itch-scratch process still remains to be fully elucidated $[2,4]$.

Martin Steinhoff

Msteinhoff@hamad.qa

1 Department of Dermatology and Venereology, Hamad Medical Corporation, Doha, Qatar

2 Dermatology Institute, Hamad Medical Corporation, Doha, Qatar

3 Translational Research Institute, Academic Health System, Hamad Medical Corporation, Doha, Qatar

4 Weill Cornell Medicine-Qatar, Doha, Qatar

5 Medical School, Qatar University, Doha, Qatar

6 School of Medicine, Weill Cornell Medical College, New York, NY, USA
The development of effective treatments for chronic pruritus will depend on deepening our knowledge on the underlying pathways and mechanisms and ways in which these can be targeted to create novel or more effective therapeutics. This review provides a brief overview of the pathogenesis of chronic pruritus, focusing on the role of substance $\mathrm{P}$ (SP) and neurokinin 1 receptor (NK1R) signalling and the mechanisms by which NK1R antagonists target this pathway. Furthermore, we discuss the efficacy, safety and tolerability of current NK1R antagonists, which have been used in the clinic for treating pruritus thus far. We elaborate how NK1R antagonism may provide a promising therapeutic option for the treatment of chronic pruritus resulting from various disorders, based on clinical trials and reports.

\subsection{Chronic Pruritus}

Chronic pruritus is estimated to affect approximately $22 \%$ of the general population at some point in their lifetime [5]. The pathogenesis of chronic pruritus is complex and can result from an underlying disease directly affecting the skin, i.e. atopic dermatitis, psoriasis, urticaria, epidermolysis bullosa or systemic diseases such as chronic liver disease, hyperthyroidism, lymphoma and neurological disease, to name a few $[1,6,7]$. Itch can also arise from unknown causes as well as from psychological disorders [1]. An established distinction 


\section{Key Points}

Chronic pruritus is a very common symptom of numerous dermatological and systemic disorders, resulting in a significant impairment in patient's quality of life.

Current treatments for chronic and recalcitrant pruritus are inadequate and there is a pressing need for the development of therapeutics with better efficacy.

Neurokinin 1 receptor (NK1R) and its endogenous ligand substance $\mathrm{P}(\mathrm{SP})$ is a key pathway of pruritus in skin and likely acts more via the CNS.

NK1R antagonists are a class of drugs that can target and reduce itch-induced signalling, and increasing data indicate their potential in treating chronic pruritus.

is that on a cellular level, itch can be defined as either histaminergic and non-histaminergic $[1,2]$ and further divided as itch induced by a healthy nervous system via peripheral and central mechanisms (pruriceptive and neurogenic/systemic respectively), compared to itch caused by diseased neurons (neuropathic) [1,8].

\section{Substance P, Neurokinin Receptors and Itch}

The tachykinin peptides family is one of the largest and most prominently studied of the neuropeptides. SP was the first neuropeptide to be isolated from brain tissue in 1931 [9, 10]. It is the first member of the tachykinin peptide family, along with neurokinin A (NKA) and neurokinin B (NKB) and is considered a 'pioneering neuropeptide' due to the subsequent studies of tachykinins shedding greater light on the function and role of neuropeptides [11]. Additional tachykinins identified in the Tac genes include NP, haemokinin-1 (HK-1) and the $\mathrm{NH}_{2}$-terminally extended forms of HK-1, which include endokinin A (EKA) and B (EKB) [11].

$\mathrm{SP}$ acts as a neurotransmitter/modulator in the central and peripheral nervous system in mammals and is produced by neuronal and non-neuronal cells $[11,12]$. It is involved in a diverse range of responses, such as nausea, depression, vomiting, pain, neurogenic inflammation, and as recently described, itch $[8,9,11,12]$. The biological activity of SP is predominantly mediated via NKRs, also known as tachykinin receptors (TACRs). NKRs belong to the class I family of G-protein coupled receptors (GPCRs). There are three different NKRs (NK1R, NK2R and NK3R), each with differing binding affinity to SP, NK1R with the highest affinity and
NK3R the lowest [11]. The NK1R is found in two isoforms in humans, one being the full-length receptor (NK1R) and the other existing in a truncated form (NK1R-T), which has been detected in different cells and regions [11, 13].

\subsection{Mechanism of Action}

SP is a key mediator of skin neurogenic inflammation [14] and is produced and secreted by nerve fibres. It acts via binding to two types of receptors associated with pruritic signalling: NKRs and the Mas-related $G$ protein-coupled receptors (MRGPRs) [13, 15-18]. NK1R is expressed in numerous cell populations in the skin and implicated in pruritus such as keratinocytes, endothelial cells, mast cells, fibroblasts as well as sensory nerve endings [13, 19-21]. In rodents, studies have demonstrated high expression of NK1R in the superficial dorsal horn of the spinal cord, including the outer lamina I [22]. The binding of SP to NK1R on the aforementioned cell types in the skin, leads to mast cell degranulation thereby stimulating release of pruritogenic, proinflammatory factors such as histamine, interferon- $\gamma$, leukotriene B4, vascular endothelial growth factor (VEGF) and nerve growth factor (NGF). This causes vasodilation of blood vessels and neurogenic inflammation, clinically presented as pruritus, erythema and oedema [23-25]. In addition, proteases such as kallikreins, tryptase and trypsins can stimulate release of SP from sensory nerve endings resulting in neurogenic inflammation [26].

Upregulation of NK1R has been reported in the skin of patients suffering from chronic prurigo/prurigo nodularis $[25,27]$ and SP serum levels are enhanced in chronic urticaria [28]. A study investigating the levels of SP, NKA, NK1R and NK2R in plaque psoriasis found an increase of their levels in nerves and non-neuronal inflammatory cells in lesional skin compared to non-lesional [29]. Interestingly, the level of expression correlated with intensity of pruritus, which was measured prior to biopsy [29], suggesting a possible role of SP/NK1R in psoriasis and pruritus. Furthermore, RNA sequencing from lesional skin in patients with psoriasis and atopic dermatitis (AD) found increased levels of both SP and NK1R [30], further consolidating the importance of $\mathrm{SP}$ and NK1R in pruritus and pruritus-associated diseases.

\section{NK1R Antagonists}

NK1R antagonists are a class of drugs that exhibit numerous properties, including antiemetic, antidepressant, anxiolytic and antipruritic activity, while failing in efficacy as analgesics in human. Initially developed to treat depression, the first approved NK1R antagonist was aprepitant, which later showed efficacy and was therefore approved for the prevention of chemotherapy-induced nausea and vomiting (CINV) [31]. 


\subsection{Mechanism of Action}

Aprepitant and other NK1R antagonists (see below) act centrally by crossing the blood-brain barrier, selectively binding to and occupying NK1R receptors with different affinities in vomiting centres within the CNS, thereby blocking activation by SP, which is released as an unwanted result due to chemotherapy treatment $[31,32]$. Aprepitant has been shown to have no affinity for serotonin, corticosteroid or dopamine receptors [33, 34]. Following the development of aprepitant for the treatment of CINV, it was subsequently reported to also have antipruritic effects in a small number of patients with Sézary syndrome, an aggressive form of cutaneous T-cell lymphoma (CTCL) (Table 1) [35].

Consequently, the development of additional and novel NK1R antagonists such as serlopitant (Table 2), tradipitant and ovrepitant (Table 3) has shown potential in reducing pruritus in various disorders.

\subsection{Aprepitant}

\subsubsection{CTCL}

From the currently available NK1R antagonists, aprepitant has been the most widely investigated for the treatment of pruritus resulting from various conditions (see Table 1). Following the report of its antipruritic effects in a small number of patients with Sézary syndrome [35], numerous additional studies have also demonstrated its effect in reducing pruritus in cases of CTCL. Pruritus is a common symptom of CTCL and can be distressing and often debilitating [36]. A retrospective, non-controlled study in 17 patients with CTCL, reported a reduction in pruritic activity following treatment with aprepitant [37]. Clinical response was assessed using Patient's Global Assessment (PtGA) and a quantitative numerical scale (Squant), similar to the Visual Analogue Scale (VAS), where 0 indicates no pruritus and 10 indicates the worst pruritus imaginable. The authors also reported that the stage of CTCLs correlated with the antipruritic response, with patients at stages IB-IIB scoring lower that those at stages III-IV, both after 1 week and one month of treatment [37]. However, this was a limited, noncontrolled study, with a small number of patients who were also receiving other concomitant antipruritic treatments. Adverse events (AEs) reported were self-limited headache or mild drowsiness. Interestingly, the study reported patients with lymphomas limited to skin (stages IB-IIB) and non-erythrodermic cutaneous lesions had responded best, supporting the hypothesis that the skin plays a significant role in the anti-pruritic activity of NK1R antagonists [37].

Several other studies have also reported the antipruritic effect of aprepitant in treating CTCLs (Table 1). A female patient with chronic pruritus due to mycosis fungoides (MF) was reported to have reduced pruritus following treatment with aprepitant [38]. Another study reported a patient with refractory chronic pruritus secondary to CTCL treated with aprepitant for 3 consecutive days (125 mg on Day 1 and 80 mg on Days 2 and 3), who showed significant improvement in pruritic response based on the VAS score [39]. Following evaluation every 2 weeks, they reported a score of 3 , as compared to 10 when first undergoing treatment with aprepitant [39]. Four of five patients with pruritus secondary to erythrodermic CTCL treated with aprepitant for 3 days on a biweekly regimen, reported improvement in pruritus [40]. A study on the use of aprepitant $(80 \mathrm{mg})$ in two patients with Sézary syndrome reported antipruritic responses in both patients [41]. Assessment after 5 days showed a reduction in the VAS score from 8 and 9 before treatment, which reduced to 2 and 3, respectively. In addition, the Dermatology Life Quality Index (DLQI) questionnaire was also utilised (10 questions to assess impact of a skin disease on QoL, from 0 to 30 with a higher score indicating worse outcomes), with scores decreasing from 24 to 6 and from 22 to 8 [41].

In contrast, patients with Sèzary Syndrome taking part in a randomised, double-blind placebo controlled, cross-over clinical trial, where placebo or aprepitant were given daily for 7 days, reported an increase in pruritic activity after 7 days [42]. However, the authors acknowledged that the study had numerous limitations, the obvious one being that only 5 patients could be recruited. In addition, they attributed differences in clinical response to previous studies showing antipruritic response due to factors such as disease activity at baseline, as well conditions such as humidity and temperature [42].

\subsubsection{Anti-cancer Drugs}

It has been reported that patients with non-small-cell lung cancer undergoing treatment with erlotinib, treatment with oral aprepitant (standard doses) led to the erlotinib-induced pruritus becoming cured [43]. Subsequently, this was followed by a pilot study to investigate the use of aprepitant for treating pruritus induced by biological anticancer drugs. In a small cohort of patients with metastatic solid tumours treated with several biological anticancer drugs (cetuximab, erlotinib, gefitinib, imatinib, or sunitinib) [44], patients were classified into either a refractory group (for patients with pruritus refractory to standard treatment), or a naïve group (for patients who had not undergone treatment for pruritus). A short treatment period with aprepitant at a dosage of 125 $\mathrm{mg}$ on Day 1, $80 \mathrm{mg}$ on Day 3 and $80 \mathrm{mg}$ on Day 5, was given to patients in the refractory group following at least 1 week of standard systemic treatment, with the same schedule and dosage given to the naïve group after first onset of severe pruritus. The intensity of itch was evaluated by VAS score. The median VAS was reduced from a score of 8 to a 


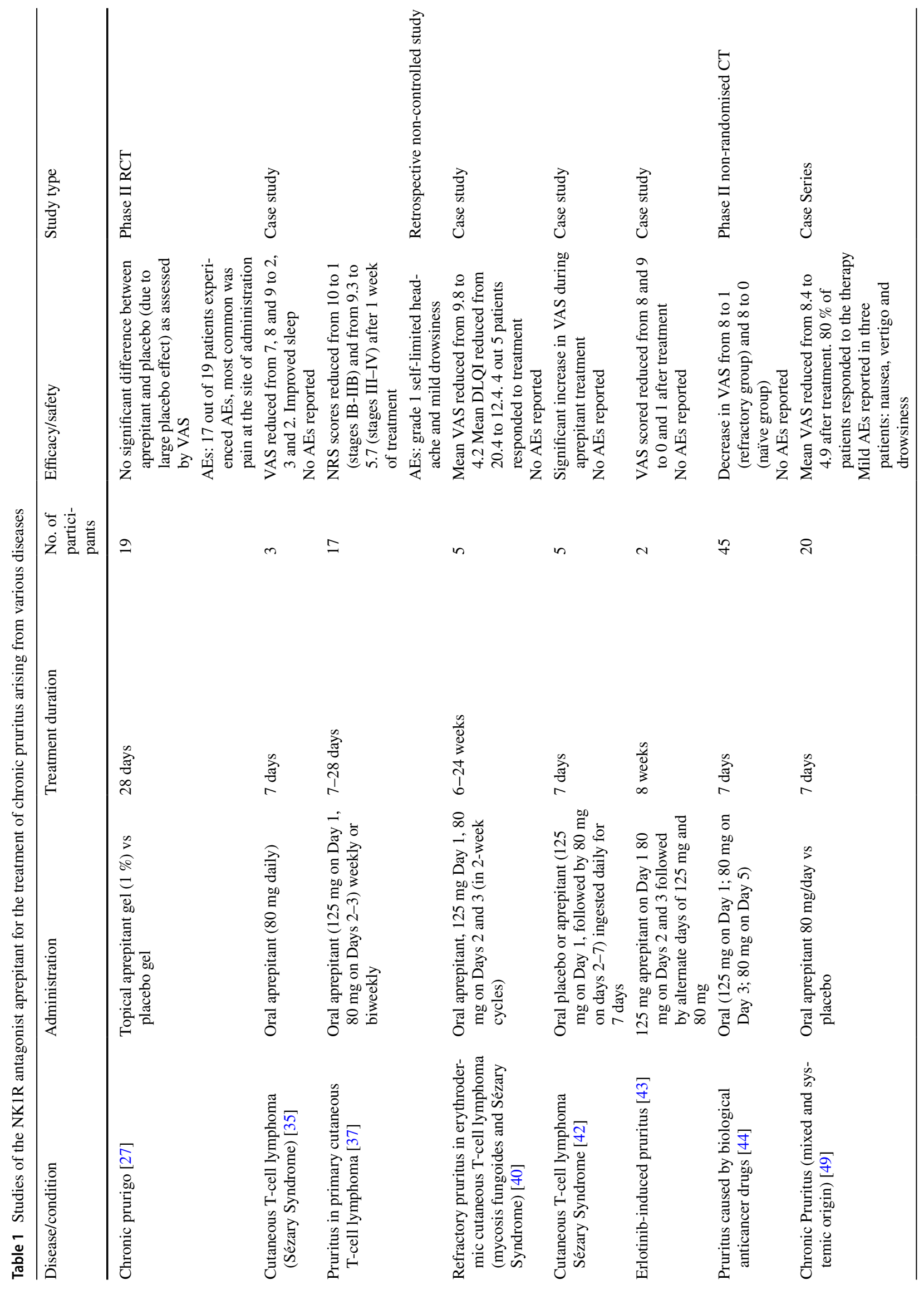




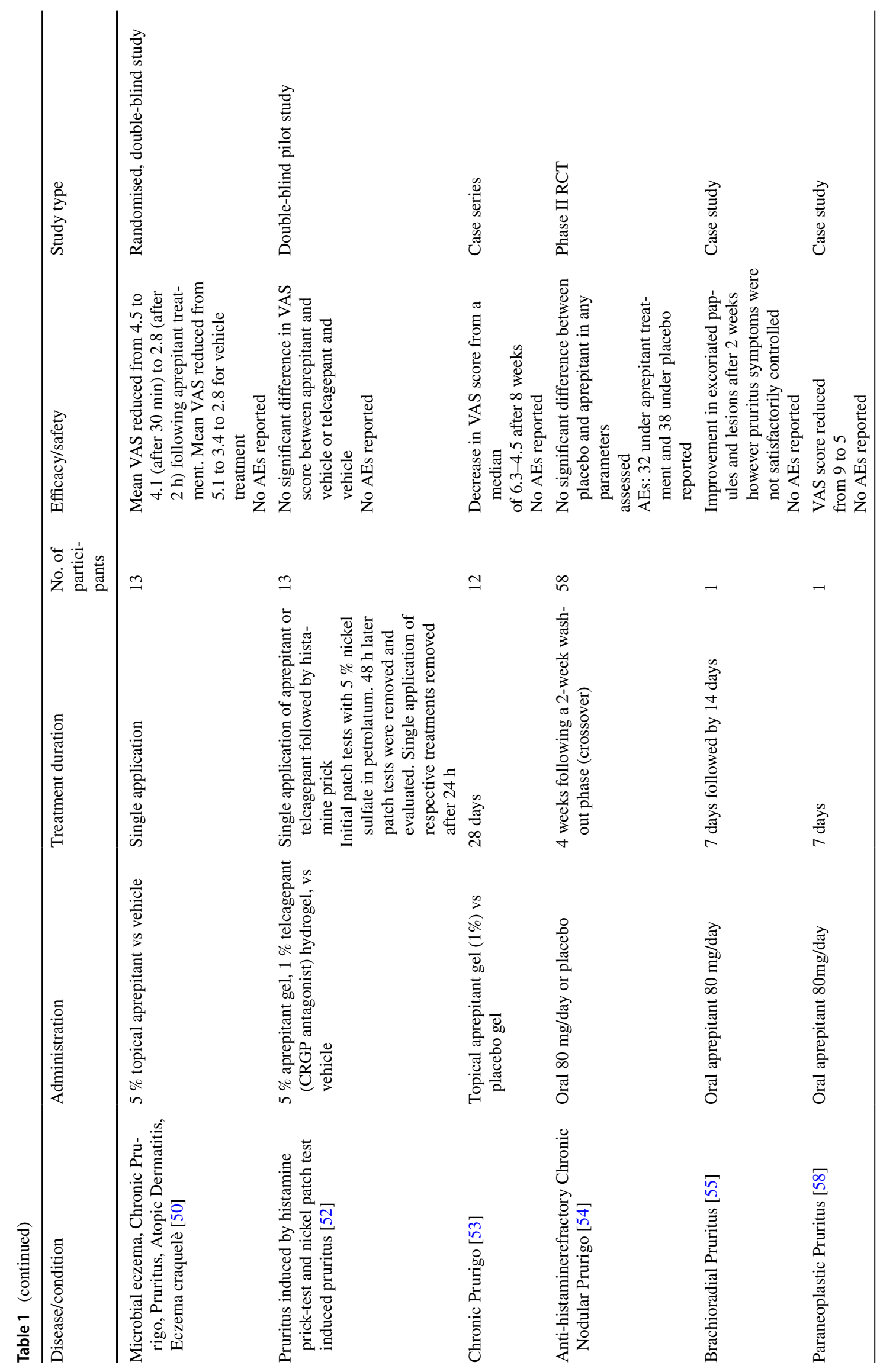


626

M. Alam et al.

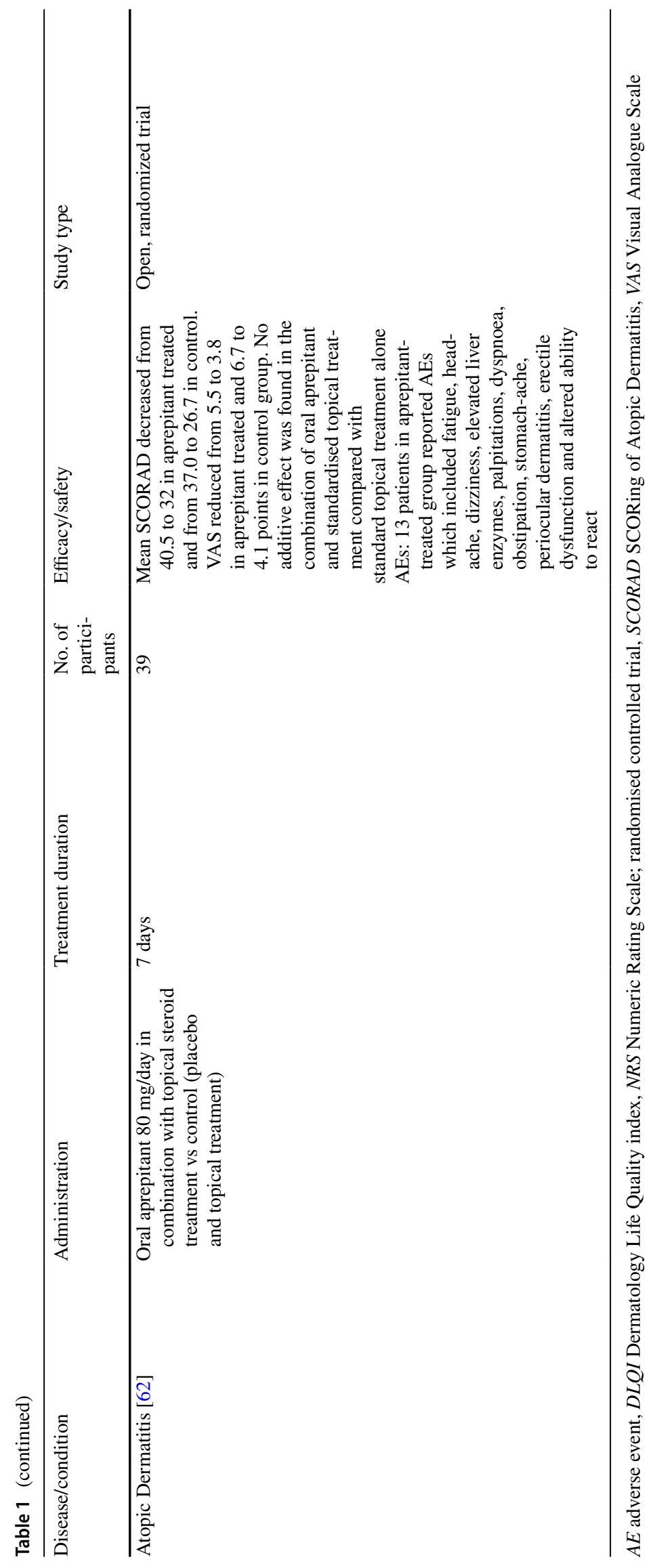

$\triangle$ Adis 
Table 2 Studies using the NK1R antagonist serlopitant for the treatment of chronic pruritus resulting from various diseases

\begin{tabular}{|c|c|c|c|c|c|}
\hline Disease/Condition & Administration & Treatment duration & $\begin{array}{l}\text { No. of } \\
\text { partici- } \\
\text { pants }\end{array}$ & Efficacy/Safety & Study type \\
\hline Chronic Pruritus [65] & $\begin{array}{l}\text { Oral serlopitant, } 0.25,1, \text { or } 5 \\
\text { mg, or placebo, administered } \\
\text { once daily }\end{array}$ & 6 weeks & 222 & $\begin{array}{l}\text { Mean percentage decrease in } \\
\text { baseline VAS score was signif- } \\
\text { icantly greater in the } 1 \mathrm{mg} \text { and } \\
5 \mathrm{mg} \text { serlopitant }(P=0.022 \\
\text { and } P=0.013 \text { respectively) } \\
\text { treatment groups compared to } \\
\text { placebo } \\
\text { AEs: most common reported } \\
\text { as somnolence and mild diar- } \\
\text { rhoea }\end{array}$ & Phase II RCT \\
\hline $\begin{array}{l}\text { Treatment-refractory } \\
\text { chronic prurigo [66] }\end{array}$ & $\begin{array}{l}\text { Oral serlopitant, } 5 \mathrm{mg} \text { or placebo } \\
\text { once daily }\end{array}$ & 8 weeks & 128 & $\begin{array}{l}\text { VAS score reduced from } 7.9 \text { at } \\
\text { baseline to } 6.2,5.5 \text { and } 4.4 \text { at } \\
\text { Weeks } 2,4 \text { and } 8 \text {, respectively, } \\
\text { whilst placebo VAS score } \\
\text { decreased to } 7.1,6.5 \text { and } 6.1 \\
\text { AEs: serlopitant treatment AEs } \\
\text { included nasopharyngitis, diar- } \\
\text { rhoea and fatigue }\end{array}$ & Phase II RCT \\
\hline Psoriasis [67] & $\begin{array}{l}\text { Oral serlopitant, } 5 \mathrm{mg} \text { or placebo } \\
\text { once daily }\end{array}$ & 8 weeks & 204 & $\begin{array}{l}\text { WI-NRS scores were } 8.3 \text { for the } \\
\text { serlopitant group and } 8.1 \text { for } \\
\text { placebo. At Week } 8 \text {, patients } \\
\text { treated with serlopitant had a } \\
\text { WI-NRS 4-point response rate } \\
\text { of } 33.3 \% \text { compared to } 21 \% \text { of } \\
\text { patients treated with placebo } \\
\text { AEs: } 4.9 \% \text { occurrence in } \\
\text { serlopitant treated and } 4 \% \text { in } \\
\text { placebo treated. Most com- } \\
\text { mon AEs were diarrhoea and } \\
\text { headache at } 2.0 \% \text { each in the } \\
\text { serlopitant group vs } 1.0 \% \text { each } \\
\text { for placebo }\end{array}$ & Phase II RCT \\
\hline Epidermolysis Bullosa [71] & $\begin{array}{l}\text { Oral serlopitant } 5 \mathrm{mg} \text { daily or } \\
\text { placebo }\end{array}$ & 12 weeks & 14 & $\begin{array}{l}\text { NRS score showed a tendency } \\
\text { in reduction of pruritus in } \\
\text { serlopitant treated patients } \\
\text { compared to placebo; however, } \\
\text { no significant difference was } \\
\text { reached } \\
\text { AEs: All participants reported at } \\
\text { least } 1 \text { AE, mostly mild-to- } \\
\text { moderate in severity. Most } \\
\text { common was nausea }\end{array}$ & Phase II RCT \\
\hline
\end{tabular}

$A E$ adverse event, $C T$ clinical trial, DLQI Dermatology Life Quality index, NRS Numeric Rating Scale, $R C T$ randomised controlled trial, SCO$R A D$ SCORing of Atopic Dermatitis, VAS Visual Analogue Scale, WI-NRS Worst Itch-Numeric Rating Scale

score of 1 after 1 week of treatment with aprepitant in the refractory group. In the naïve group, the VAS was reduced from a score of $8-0$ after 1 week of treatment. The study reported a reduction in pruritus in 41 of 45 patients with a reoccurrence in only six patients. Furthermore, no AEs were reported that were due to administration of aprepitant, which demonstrated its potential as an anti-pruritic therapeutic [44]. Additionally, a case report on two patients with solid tumours (metastatic soft tissue sarcoma and metastatic breast carcinoma) suffering from pruritus, reported a decrease in
VAS scores from 8 or $9 / 10$ to $0 / 10$ and $1 / 10$, respectively, after treatment with standard doses of aprepitant [45].

\subsubsection{Chronic Prurigo}

As discussed earlier, chronic pruritus can be the result of various underlying causes. Chronic prurigo (CPG) or prurigo nodularis $(\mathrm{PN})$, is a debilitating disease resulting from long-term scratching of skin by patients suffering from chronic pruritus. It is characterized by numerous 
hyperkeratotic, highly pruritic lesions, nodules and papules $[25,46]$. It can originate from either dermatological conditions such as $\mathrm{AD}$, systemic diseases such as chronic kidney disease (CKD) or be neurological in origin [47]. However, the underlying pathophysiological cause/s are unknown [25, 48]. A recent study in 20 patients (13 of whom suffered from PN) with chronic refractory pruritus due to systemic and mixed causes, reported improvement in antipruritic response after treatment with aprepitant [49]. Following treatment with $80 \mathrm{mg} / \mathrm{day}$ aprepitant for 1 week, $80 \%$ of patients reported a reduction of itch intensity, with a statistically significant reduction in VAS score from a median of 8.4-4.9 [49]. Interestingly, patients with pruritus from dermatological diseases responded best to that treatment with only mild side effects such as nausea, vertigo and drowsiness in 3/20 patients [49].

A subsequent randomized, placebo-controlled, splitsided, double-blind clinical trial was conducted where topical $1 \%$ aprepitant solution was applied twice daily for 28 days to 19 patients with CPG [27]. Aprepitant was found to reduce intensity of pruritus with a reduction in VAS score of $-35.2 \pm 6.0(66.1 \pm 8.2 \%)$; however, reduction was also seen in placebo with a reduction of $-38.1 \pm 6.8(58.0 \pm 9.4$ $\%$ ) [27]. This was also the case for prurigo lesions, with clinical scores significantly improving in both aprepitantand placebo-treated groups. Seventeen patients experienced mild AEs and three were moderate, the most common being pain at the site of administration (55\% vs $45 \%$ ) and cutaneous reaction ( $75 \%$ vs $55 \%$ ) in aprepitant and placebo groups, respectively. No serious AEs were reported in either group [27].

An earlier study using $5 \%$ topical aprepitant in patients with clinical and experimental pruritus found no difference in antipruritic effects after topical treatment with the NK1R antagonist [50]. A single topical application of $5 \%$ aprepitant was made in 13 patients (with microbial eczema, chronic prurigo, chronic pruritus, atopic dermatitis, eczema craquelè) to investigate the hypothesis that aprepitant exerts its antipruritic effects by acting on mast cells in the skin [50, 51]. Although the application of $5 \%$ aprepitant attenuated clinical pruritus and erythema in dermatitis patients, it was no more than vehicle [50]. Additionally, no changes were seen in pruritus induced by prick-test reaction to histamine following application of $5 \%$ aprepitant [50].

An additional study by the same group examined the topical effects of aprepitant and telcagepant (CGRP antagonist) on delayed and immediate reactions of the skin and associated pruritus [52]. Thirteen healthy volunteers were treated with both aprepitant and telcagepant, each on different areas on one forearm and vehicle to the other. After 30 minutes, creams were wiped off and histamine prick tests were applied to control and treated area. Intensity and flare of itch was measured after 5 minutes via VAS score and weal 
volume after 15 minutes [52]. Patch tests were applied to patients allergic to nickel in five locations and after $48 \mathrm{~h}$ they were removed and evaluated. The areas were subsequently treated with $5 \%$ aprepitant gel and $1 \%$ telcagepant hydrogel, or vehicle, then removed after $24 \mathrm{~h}$ [52]. Neither the histamine-induced pruritus via prick test nor the nickel patch testinduced pruritus was affected by any treatment. The authors explained that this could be due to insufficient permeation of the skin by the formulation used. In addition, application of topical aprepitant would only target cutaneous NK1 receptors, as opposed to oral administration that reduced pruritus [49], likely by also targeting spinal cord and brain NK1R, although the role of peripherally expressed NK1R as compared to spinal cord and brain-expressed NK1R in humans is still not clear. The study was limited due to the low number of participants.

A study in which $12 \mathrm{PN}$ patients received $80 \mathrm{mg} /$ day aprepitant, reported a significant reduction in pruritic intensity, with a decrease in VAS score from a median of 6.3-4.5 after 8 weeks [53]. Whether a reduction of 1.8 on the NRS scale can be considered clinically meaningful must be interpreted with caution. In addition, they found an increase in NK1R expression in the keratinocytes of lesional skin compared to healthy controls. After treatment, the expression of epidermal NK1R was increased; however, the expression of downstream signalling pathways ERK1/2 decreased [53], suggesting that the antipruritic effects of aprepitant may indeed derive from a local effect in tandem with acting in the CNS.

Recently, a multicentre, randomized, double-blind, placebo-controlled, cross-over, Phase II trial was conducted to investigate the antipruritic effects of aprepitant in 58 patients with antihistamine-refractory chronic pruritus in chronic nodular prurigo. The authors found no difference between the placebo and aprepitant groups [54]. No significant differences were found in the VAS score between aprepitant or placebo groups nor in other parameters such as prurigo lesions or QoL [54]. Although a reduction in pruritus intensity was seen after the first treatment period, as measured by VAS score, the second treatment period led to a slight increase in pruritus intensity after aprepitant treatment. The authors explained several reasons for this; (1) patients were aware that they would receive either the drug or a placebo, and therefore knew that the results would be either negative or positive, thus producing a possible nocebo effect, which may have hampered antipruritic effects [54]; (2) they also suggested that a high level of negative expectation and a lack of trust in novel therapies by patients suffering from CPG may have hindered the results, as treatment during the first period led to a decrease in pruritus, whereas no change was observed in the second period [54].

Case reports have shown mixed results. Single case reports demonstrated a reduction of pruritus under aprepitant in a patient with refractory brachioradial pruritus [55] or localised neuropathic dysesthesia in the upper extremities [56]. Patients were given $80 \mathrm{mg}$ /day aprepitant for 7 days, with improvement in scratch lesions and pruritus after 2 days. However, rapid relapses occurred two days after the last dose. A second course was commenced; in the following 2 weeks papules and erosions improved. However, it was reported that pruritic symptoms were not well controlled [55]. No AEs were reported and a 6-week follow-up found that lesions remained improved, although the level of improvement was weakly defined [55].

\subsubsection{Pruritus of Unknown Origin}

In a report on a patient suffering from chronic pruritus of unknown origin, histopathological analysis showed superficial psoriasiform dermatitis with spongiosis and parakeratosis [57]. Following treatment with $125 \mathrm{mg}$ aprepitant on Day 1 and $80 \mathrm{mg}$ on Days 2, 3 and 4, a significant improvement in pruritus was reported. Before treatment, VAS and DLQI score values were 8 and 24, respectively. Improvement was seen after just 24 hours with values decreasing to 4 and 16, respectively. After 6 weeks, VAS and DLQI were further decreased to 1 and 8, respectively. This was associated with improvement in cutaneous lesions [57]. The patient did not experience AEs and sleep quality was greatly improved. The use of aprepitant in treating paraneoplastic pruritus has also been reported in a single patient [58]. Administration of 80 $\mathrm{mg} /$ day aprepitant for 14 days reduced the VAS score from 9 to 5, improving the patient's QoL [58].

\subsubsection{Atopic Dermatitis}

Atopic dermatitis (AD) is one of the most common inflammatory skin disorders world-wide, characterised by severe pruritus, barrier disruption, xerosis and inflammation [59-61]. An open, randomised study investigating the effects of aprepitant in combination with a standardised topical treatment using topical glucocorticosteroid and moisturiser in patients with moderate-severe $\mathrm{AD}$, found no additive effect with concomitant NK1R treatment [62]. The treatment group consisted of 19 patients who were administered 80 $\mathrm{mg}$ /day aprepitant and topical steroid for 7 days, compared to control patients who received topical treatment alone. Clinical response was measured using SCORing of Atopic Dermatitis (SCORAD) and VAS score. In both, control- and aprepitant-treated groups there was a decrease in SCORAD and VAS score. However, no significant additional improvement was seen in aprepitant-treated group compared to control [62]. Thirteen patients in aprepitant-treated group reported AEs, which included fatigue, headache, dizziness, elevated liver enzymes, palpitations, dyspnoea, obstipation, stomach-ache, periocular dermatitis, erectile dysfunction 
and altered ability to react. All AEs were considered mild to moderate. All AEs were reported to be transient, except for one case of elevated liver enzymes, which remained above normal at the last follow-up visit [62].

A subsequent study by the group investigated the expression of tachykinin markers in AD skin and whether they correlate with clinical and psycho-demographic parameters [63]. In biopsies from lesional skin of AD patients, they found an increase in the number of SP- and NKA-positive nerve fibres and NKA-positive mononuclear dermal cells, compared to non-lesional skin. Moreover, the depression score and the number of dermal NK1R-positive cells in lesional and non-lesional skin showed a positive correlation [63].

\subsection{Serlopitant}

Serlopitant, an NK1R antagonist, was originally developed for the treatment of urinary incontinence and overactive bladder [64]. As compared to aprepitant, serlopitant has a higher affinity to the NK1R in the low nanomolar range [11]. We recently completed a multicentre, placebo-controlled, double-blind, randomised, Phase II clinical trial in patients with chronic refractory pruritus to investigate the safety and antipruritic efficacy of serlopitant (Table 2). In total, 222 patients received serlopitant $0.25 \mathrm{mg} /$ day (64 patients), $1 \mathrm{mg} /$ day (65 patients), $5 \mathrm{mg} /$ day (64 patients), and the remaining patients received placebo [65]. After 6 weeks, mean percentage decrease in baseline VAS score was significantly greater in the $1 \mathrm{mg}$ and $5 \mathrm{mg}$ serlopitant treatment groups compared to placebo. Good tolerability was observed, and the most common AEs reported were somnolence and mild diarrhoea. The beneficial effects on pruritus intensity remained 4 weeks after treatment follow-up [65]. A recent, randomised, double-blind, placebo-controlled study assessed safety and efficacy of serlopitant for the treatment of pruritus in PN [66]. For 8 weeks, serlopitant $5 \mathrm{mg} /$ day or placebo was administered to 128 patients (65 patients received serlopitant and 63 received placebo) with chronic, refractory PN. The change in average VAS score was used as the primary end point at Weeks 4 and 8. At baseline, average VAS score was 7.9/10, which decreased in the serlopitant treatment group at Weeks 2, 4 and 8-6.2, 5.5 and 4.4/10, respectively, whilst placebo VAS score decreased to 7.1, 6.5 and 6.1 [66]. There was a statistically significant decrease in pruritus intensity at Weeks 4 and 8 in serlopitant-treated groups compared to placebo. A limitation of the study was the short duration period of treatment, which the authors suggest may not be long enough to assess clinically relevant resolution of PN lesions. However, treatment with serlopitant reduced pruritic intensity and was well tolerated after 6 weeks.
More recently, a randomised, double-blind, placebo-controlled, Phase II trial was performed to assess serlopitant for the treatment of patients with mild-to-moderate psoriasis [67]. For 8 weeks, 102 patients were administered oral serlopitant $5 \mathrm{mg} /$ day and 102 patients received placebo. At baseline, mean WI-NRS (Worst Itch-Numerical Rating Score) scores were 8.3 for the serlopitant group and 8.1 for placebo. At Week 8, patients treated with serlopitant had a WI-NRS 4-point response rate of $33.3 \%$ compared to $21 \%$ of patients treated with placebo [67]. Moreover, at Week 4, WI-NRS scores were $20.8 \%$ of patients treated with serlopitant compared to $11.5 \%$ for placebo-treated patients. AEs occurred in $4.9 \%$ of serlopitant-treated patients and $4 \%$ of patients treated with placebo. Overall, serlopitant treatment was well tolerated and reduced pruritus associated with mild-to-moderate psoriasis. However, severe psoriasis was excluded from the study and the study population was small [67].

Furthermore, two Phase III clinical trials to assess serlopitant for the treatment of PN did not meet the primary endpoint of a 4-point improvement from baseline at Week 10 on the WI-NRS and thus a significant reduction of pruritus [68, 69]. In study MTI-105 (NCT3546816), 26.45\% of patients treated with serlopitant achieved a 4-point or greater improvement on the WI-NRS at Week 10 compared to baseline compared to $20.31 \%$ in placebo $(P=0.229)$ [68]. In study MTI-106 (NCT03677401), administration of $5 \mathrm{mg}$ serlopitant achieved a 4-point responder rate at Week 10 in $25.9 \%$ of patients compared to $18.95 \%$ of the placebo group. Although a reduction was seen, this was not significant $(P=0.158)[69]$.

Epidermolysis bullosa (EB) is a group of diverse, rare, inherited skin disorders, resulting from mutations in genes encoding, for example, for laminin, keratin and collagen [70]. Pruritus is one of the common symptoms across all EB subtypes and is considered to be the most distressing of disease-related symptoms and when chronic, can cause major morbidities [70]. A Phase II, randomised clinical trial to assess safety and efficacy of serlopitant in treating moderate-to-severe pruritus in EB, reported potential itch reduction [71]. A total of 14 patients were randomised to $5 \mathrm{mg} /$ day serlopitant or placebo for 8 weeks followed by a 4-week washout. The primary endpoint was change in itch intensity, which was measured by the Numeric Rating Scale (NRS). Serlopitant treatment led to greater reduction in pruritus; however, it did not reach statistical significance [71]. Although serlopitant treatment did not reach significance in reducing pruritus, possibly due to small sample size (due to disease rarity), it may be a promising therapeutic option in treating chronic pruritus in EB and warrants a larger trial, which is currently underway [72]. 


\subsection{Tradipitant}

Tradipitant (VLY-686) is another NK1R antagonist, which has been investigated for its antipruritic activity (Table 3). A randomised, double-blind, placebo-controlled, multicentre, Phase II trial investigating safety and efficacy of tradipitant in AD patients found a significant improvement in itch, disease severity and QoL in patients with refractory AD [73]. In 168 patients, VAS score and SCORAD improved in patients treated with tradipitant compared to placebo (Table 3) [73]. In a subsequent Phase III clinical trial (EPIONE) in 341 patients, the antipruritic effect of tradipitant was not seen in moderate or severe AD, the study did not reach the primary endpoint of reducing pruritus in the overall study population [74]. However, in patients suffering from mild AD, tradipitant significantly improved itch and sleep. The study reported that over $70 \%$ of patients with mild AD had improved pruritus after the first day of treatment [74].

\subsection{Orvepitant}

An additional NK1R antagonist, orvepitant, was developed as an anti-depressant but efficacy was not great enough to continue development $[75,76]$. Preclinical data from a Mongolian Gerbil model of scratching behaviour administered with orvepitant found a profound antipruritic effect with the inhibition of hindlimb scratching [77]. A subsequent randomised, double-blind, placebo-controlled clinical trial was undertaken to evaluate the efficacy of orvepitant for epidermal growth factor receptor inhibitor (EGFRI)-induced pruritus [78] (Table 3). Oral orvepitant, 10 or $30 \mathrm{mg} / \mathrm{day}$, was given for 4 weeks and compared to placebo in 44 patients. Although orvepitant was safe and well tolerated, there was no significant difference in antipruritic effects as assessed by NRS score between orvepitant and placebo at either dosage [78].

\section{Conclusions and Future Perspectives}

It is now well-known that SP is released and NK1R is expressed in skin, spinal cord and brain. In the skin, SP is released by sensory nerve endings in the epidermis and dermis, thereby modulating the function of immune cells, keratinocytes and endothelial cells resulting in neurogenic inflammation $[11,14]$. In addition, SP may be an important inducer of peripheral itch, thus, a key player in pruritic signalling. Consequently, NK1R antagonists have gained traction recently for treating chronic and recalcitrant pruritus [19, 79]. Although the use of topical aprepitant did not support the hypothesis that it may act predominantly on skin, it suggests that topical aprepitant likely functions in reducing pruritus by predominantly acting on central
NK1R activity. This has been demonstrated by the multiple studies showing reduction in pruritus following treatment via oral administration with the currently available NK1R antagonists (aprepitant, tradipitant, serlopitant and orvepitant). However, whether the main inhibitory function will be in the spinal cord or brain remains to be determined. This location of the inhibitory function may also explain the success of NK1R antagonists in mild-to-moderate psoriasis and $\mathrm{AD}$ compared to more severe pruritic conditions, where other mechanisms and regulators may play a significant role. In addition, as mentioned in the introduction, SP not only binds to the NK1R but also to MRGPRs, which also have a role during inflammation [80]. Thus, a potential reason for the lack of efficacy seen in clinical studies using NK1R antagonists maybe due to the role of MRGPRs (possibly via MRGPRX2) in certain pruritic conditions. Therefore, the development of MRGPR antagonists and their antipruritic potential in particular, where NK-1R antagonists have not been successful, deserve to be investigated.

Furthermore, the use of other NK1R antagonists via topical application other than aprepitant, remains to be investigated, especially in larger-scale trials of many different pruritic diseases. The anecdotal rapid onset of marked itch improvement, as compared to other oral antipruritic drugs, is still encouraging to further study potential benefits in some pruritic diseases and maybe some subforms (e.g., better responses in mild-to-moderate than severe $\mathrm{AD}$ ). In general, all NK1R antagonists studied have shown favourable tolerability, with adverse events presenting as mild or moderate. Several study results must be interpreted with caution given they are limited, with a small number of participants, lack of controls, allowed addition of topicals, or a short time period of treatment. Thus, larger and better-designed studies/clinical trials are still required.

Overall, NK1R antagonists have demonstrated antipruritic activity in treating chronic pruritus of various origins and further studies will help to define the best treatment regimen and the best diseases to treat via NK1R antagonism. The importance of knowing the similarities, differences and underlying pathophysiological mechanisms of different pruritic diseases, whether dermatological or systemic in origin, will help to enhance the development of antipruritic therapies. Furthermore, expanding our knowledge on the structure and biochemistry of NK1R will help drug development targeting of this receptor [81]. As chronic pruritus is a major symptom that significantly impacts patient's QoL, often recalcitrant, more effective and safe therapeutic options are still required.

Acknowledgement This work was supported by grants of the Medical Research Centre, Academic Health System at Hamad Medical Corporation to MS/JB (IRGC-04-SI-17-151) and the Qatar National Research Fund, a member of Qatar Foundation, to MS/JB (NPRP11S-0117-180326). 


\section{Declarations}

Funding Open access funding provided by the Qatar National Library. This work was supported by grants of the Medical Research Center, Academic Health System at Hamad Medical Corporation to MS/JB (IRGC-04-SI-17-151) and the Qatar National Research Fund, a member of Qatar Foundation, to MS/JB (NPRP11S-0117-180326).

Conflicts of interest MS has received grants from Abvie, Galderma and Pfizer; honoraria for serving as a consultant for Abvie, Galderma, Pfizer, Sanofi, Janssen, Lilly and Leo Pharma. MA, JB and FA have no conflicts of interest or disclosures.

Ethics approval Not applicable.

Consent to participate Not applicable.

Consent to publish Not applicable.

Availability of data and material Not applicable.

Code availability Not applicable.

Author contributions Manuscript was written by MA and MS with contribution from JB and FA.

Open Access This article is licensed under a Creative Commons Attribution-NonCommercial 4.0 International License, which permits any non-commercial use, sharing, adaptation, distribution and reproduction in any medium or format, as long as you give appropriate credit to the original author(s) and the source, provide a link to the Creative Commons licence, and indicate if changes were made. The images or other third party material in this article are included in the article's Creative Commons licence, unless indicated otherwise in a credit line to the material. If material is not included in the article's Creative Commons licence and your intended use is not permitted by statutory regulation or exceeds the permitted use, you will need to obtain permission directly from the copyright holder. To view a copy of this licence, visit http://creativecommons.org/licenses/by-nc/4.0/.

\section{References}

1. Ikoma A, Steinhoff M, Ständer S, Yosipovitch G, Schmelz M. The neurobiology of itch. Nat Rev Neurosci. 2006;7:535-47.

2. Yosipovitch G, Rosen JD, Hashimoto T. Itch: From mechanism to (novel) therapeutic approaches. J Allergy Clin Immunol. 2018;142:1375-90.

3. Reich A, Misery L, Takamori K. Pruritus: From the Bench to the Bedside. Biomed Res Int. 2018;2018:5742753.

4. Steinhoff M. Inflammation, Immunology and Allergy. Rook's Textbook of Dermatology, Ninth Edition [Internet]. American Cancer Society; 2016. p. 1-78. https://doi.org/10.1002/97811 18441213.rtd0008

5. Weisshaar E. Epidemiology of Itch. Curr Probl Dermatol. 2016;50:5-10.

6. Ayasse MT, Buddenkotte J, Alam M, Steinhoff M. Role of neuroimmune circuits and pruritus in psoriasis. Exp Dermatol. 2020;29:414-26.

7. Yosipovitch G, Berger T, Fassett MS. Neuroimmune interactions in chronic itch of atopic dermatitis. J Eur Acad Dermatol Venereol. 2020;34:239-50.
8. Steinhoff M, Oaklander AL, Szabó IL, Ständer S, Schmelz M. Neuropathic itch. Pain. 2019;160(Suppl 1):S11-6.

9. Nässel DR, Zandawala M, Kawada T, Satake H. Tachykinins: neuropeptides that are ancient, diverse, widespread and functionally pleiotropic. Front Neurosci. 2019;13:1262.

10. Euler VUS, Gaddum JH. An unidentified depressor substance in certain tissue extracts. J Physiol (Lond). 1931;72:74-87.

11. Steinhoff MS, von Mentzer B, Geppetti P, Pothoulakis C, Bunnett NW. Tachykinins and their receptors: contributions to physiological control and the mechanisms of disease. Physiol Rev. 2014;94:265-301.

12. Graefe S, Mohiuddin SS. Biochemistry, Substance P. StatPearls [Internet]. Treasure Island (FL): StatPearls Publishing; 2020 [cited 2020 Jun 16]. http://www.ncbi.nlm.nih.gov/books/NBK554583/. Accessed 16 June 2020.

13. Suvas $\mathrm{S}$. Role of substance $P$ neuropeptide in inflammation, wound healing, and tissue homeostasis. J Immunol. 2017;199:1543-52.

14. Steinhoff M, Ständer S, Seeliger S, Ansel JC, Schmelz M, Luger T. Modern aspects of cutaneous neurogenic inflammation. Arch Dermatol. 2003;139:1479-88.

15. Azimi E, Reddy VB, Pereira PJS, Talbot S, Woolf CJ, Lerner EA. Substance $P$ activates Mas-related $G$ protein-coupled receptors to induce itch. J Allergy Clin Immunol. 2017;140(447-453):e3.

16. Steinhoff M, Buddenkotte J, Lerner EA. Role of mast cells and basophils in pruritus. Immunol Rev. 2018;282:248-64.

17. Gherardini J, Uchida Y, Hardman JA, Chéret J, Mace K, Bertolini $\mathrm{M}$, et al. Tissue-resident macrophages can be generated de novo in adult human skin from resident progenitor cells during substance P-mediated neurogenic inflammation ex vivo. PLoS ONE. 2020;15:e0227817.

18. McNeil B, Dong X. Mrgprs as Itch Receptors. In: Carstens E, Akiyama T, editors. Itch: mechanisms and treatment [Internet]. Boca Raton (FL): CRC Press/Taylor \& Francis; 2014 [cited 2020 Jul 21]. http://www.ncbi.nlm.nih.gov/books/NBK200929/. Accessed 07 Feb 2021.

19. Ständer $S$, Yosipovitch G. Substance $P$ and neurokinin 1 receptor are new targets for the treatment of chronic pruritus. Br J Dermatol. 2019;181:932-8.

20. Scholzen TE, Steinhoff M, Bonaccorsi P, Klein R, Amadesi S, Geppetti P, et al. Neutral endopeptidase terminates substance $\mathrm{P}$-induced inflammation in allergic contact dermatitis. J Immunol. 2001;166:1285-91.

21. Scholzen T, Armstrong CA, Bunnett NW, Luger TA, Olerud JE, Ansel JC. Neuropeptides in the skin: interactions between the neuroendocrine and the skin immune systems. Exp Dermatol. 1998;7:81-96.

22. Ikoma A, Cevikbas F, Kempkes C, Steinhoff M. Anatomy and neurophysiology of pruritus. Semin Cutan Med Surg. 2011;30:64-70.

23. Ständer S, Raap U, Weisshaar E, Schmelz M, Mettang T, Handwerker H, et al. Pathogenesis of pruritus. J Dtsch Dermatol Ges. 2011;9:456-63.

24. Choi JE, Di Nardo A. Skin neurogenic inflammation. Semin Immunopathol. 2018;40:249-59.

25. Zeidler C, Ständer S. The pathogenesis of Prurigo nodularis'Super-Itch' in exploration. Eur J Pain. 2016;20:37-40.

26. Steinhoff M, Vergnolle N, Young SH, Tognetto M, Amadesi $\mathrm{S}$, Ennes HS, et al. Agonists of proteinase-activated receptor 2 induce inflammation by a neurogenic mechanism. Nat Med. 2000;6:151-8.

27. Ohanyan T, Schoepke N, Eirefelt S, Hoey G, Koopmann W, Hawro T, et al. Role of substance $\mathrm{P}$ and its receptor neurokinin 1 in chronic prurigo: a randomized, proof-of-concept, controlled trial with topical aprepitant. Acta Derm Venereol. 2018;98:26-31.

28. Metz M, Krull C, Hawro T, Saluja R, Groffik A, Stanger C, et al. Substance $\mathrm{P}$ is upregulated in the serum of patients with chronic spontaneous urticaria. J Invest Dermatol. 2014;134:2833-6. 
29. Amatya B, El-Nour H, Holst M, Theodorsson E, Nordlind K. Expression of tachykinins and their receptors in plaque psoriasis with pruritus. Br J Dermatol. 2011;164:1023-9.

30. Nattkemper LA, Tey HL, Valdes-Rodriguez R, Lee H, Mollanazar $\mathrm{NK}$, Albornoz C, et al. The genetics of chronic itch: gene expression in the skin of patients with atopic dermatitis and psoriasis with severe itch. J Invest Dermatol. 2018;138:1311-7.

31. Hargreaves R, Ferreira JCA, Hughes D, Brands J, Hale J, Mattson $\mathrm{B}$, et al. Development of aprepitant, the first neurokinin-1 receptor antagonist for the prevention of chemotherapy-induced nausea and vomiting. Ann N Y Acad Sci. 2011;1222:40-8.

32. Aziz F. Neurokinin-1 receptor antagonists for chemotherapyinduced nausea and vomiting. Ann Palliat Med. 2012;1:130-6.

33. Ritchie MK, Kohli A. Aprepitant. StatPearls [Internet]. Treasure Island (FL): StatPearls Publishing; 2020 [cited 2020 Aug 14]. http://www.ncbi.nlm.nih.gov/books/NBK551588/. Accessed 14 Aug 2020.

34. Ibrahim MA, Preuss CV. Antiemetic Neurokinin-1 Receptor Blockers. StatPearls [Internet]. Treasure Island (FL): StatPearls Publishing; 2020 [cited 2020 Aug 14]. http://www.ncbi.nlm.nih. gov/books/NBK470394/. Accessed 14 Aug 2020.

35. Duval A, Dubertret L. Aprepitant as an antipruritic agent? N Engl J Med. 2009;361:1415-6.

36. Ahern K, Gilmore ES, Poligone B. Pruritus in cutaneous T-cell lymphoma: a review. J Am Acad Dermatol. 2012;67:760-8.

37. Maroñas-Jiménez L, Estrach T, Gallardo F, Pérez A, Andrés Borja $\mathrm{H}$, Servitje O, et al. Aprepitant improves refractory pruritus in primary cutaneous T-cell lymphomas: experience of the Spanish Working Group on Cutaneous Lymphomas. Br J Dermatol. 2018;178:e273-4.

38. Jiménez Gallo D, Albarrán Planelles C, Linares Barrios M, Fernández Anguita MJ, Márquez Enríquez J, Rodríguez Mateos ME. Treatment of pruritus in early-stage hypopigmented mycosis fungoides with aprepitant. Dermatol Ther. 2014;27:178-82.

39. Borja-Consigliere HA, López-Pestaña A, Vidal-Manceñido MJ, Tuneu-Valls A. Aprepitant in the treatment of refractory pruritus secondary to cutaneous T-cell lymphoma. Actas Dermosifiliogr. 2014;105:716-8.

40. Booken N, Heck M, Nicolay JP, Klemke CD, Goerdt S, Utikal J. Oral aprepitant in the therapy of refractory pruritus in erythrodermic cutaneous T-cell lymphoma. Br J Dermatol. 2011;164:665-7.

41. Torres T, Fernandes I, Selores M, Alves R, Lima M. Aprepitant: Evidence of its effectiveness in patients with refractory pruritus continues. J Am Acad Dermatol. 2012;66:e14-15.

42. Zic JA, Straka BT, McGirt LY, Nian H, Yu C, Brown NJ. Aprepitant for the treatment of pruritus in Sézary syndrome: a randomized crossover clinical trial. JAMA Dermatol. 2018;154:1221-2.

43. Vincenzi B, Tonini G, Santini D. Aprepitant for erlotinib-induced pruritus. N Engl J Med. 2010;363:397-8.

44. Santini D, Vincenzi B, Guida FM, Imperatori M, Schiavon G, Venditti $\mathrm{O}$, et al. Aprepitant for management of severe pruritus related to biological cancer treatments: a pilot study. Lancet Oncol. 2012;13:1020-4.

45. Vincenzi B, Fratto ME, Santini D, Tonini G. Aprepitant against pruritus in patients with solid tumours. Support Care Cancer. 2010;18:1229-30.

46. Steinhoff M, Cevikbas F, Yeh I, Chong K, Buddenkotte J, Ikoma A. Evaluation and management of a patient with chronic pruritus. J Allergy Clin Immunol. 2012;130(1015-1016):e7.

47. Steinhoff M, Schmelz M, Szabó IL, Oaklander AL. Clinical presentation, management, and pathophysiology of neuropathic itch. Lancet Neurol. 2018;17:709-20.

48. Mullins TB, Sharma P, Sonthalia S. Prurigo Nodularis. StatPearls [Internet]. Treasure Island (FL): StatPearls Publishing; 2020 [cited
2020 Aug 18]. http://www.ncbi.nlm.nih.gov/books/NBK459204/. Accessed 18 Aug 2020.

49. Ständer S, Siepmann D, Herrgott I, Sunderkötter C, Luger TA. Targeting the neurokinin receptor 1 with aprepitant: a novel antipruritic strategy. PLoS ONE. 2010;5:e10968.

50. Wallengren J. Topical aprepitant in clinical and experimental pruritus. Arch Dermatol. 2012;148:957-9.

51. Gerber PA, Buhren BA, Homey B. More on aprepitant for erlotinib-induced pruritus. N Engl J Med. 2011;364:486-7.

52. Wallengren J, Edvinsson L. Topical non-peptide antagonists of sensory neurotransmitters substance P and CGRP do not modify patch test and prick test reactions: a vehicle-controlled, doubleblind pilot study. Arch Dermatol Res. 2014;306:505-9.

53. Agelopoulos K, Rülander F, Dangelmaier J, Lotts T, Osada N, Metze D, et al. Neurokinin 1 receptor antagonists exhibit peripheral effects in prurigo nodularis including reduced ERK1/2 activation. J Eur Acad Dermatol Venereol. 2019;33:2371-9.

54. Tsianakas A, Zeidler C, Riepe C, Borowski M, Forner C, Gerss J, et al. Aprepitant in anti-histamine-refractory chronic nodular prurigo: a multicentre, randomized, double-blind, placebo-controlled, cross-over, phase-II TRIAL (APREPRU). Acta Derm Venereol. 2019;99:379-85.

55. Ally MS, Gamba CS, Peng DH, Tang JY. The use of aprepitant in brachioradial pruritus. JAMA Dermatol. 2013;149:627-8.

56. Robbins BA, Schmieder GJ. Brachioradial Pruritus. StatPearls [Internet]. Treasure Island (FL): StatPearls Publishing; 2020 [cited 2020 Aug 18]. http://www.ncbi.nlm.nih.gov/books/NBK459321/. Accessed 18 Aug 2020.

57. Huh JW, Jeong Y-I, Choi K-H, Park H-J, Jue M-S. Treatment for refractory pruritus using oral aprepitant. Ann Dermatol. 2016;28:124-5.

58. Villafranca JJA, Siles MG, Casanova M, Goitia BT, Domínguez AR. Paraneoplastic pruritus presenting with Hodgkin's lymphoma: a case report. J Med Case Rep. 2014;8:300.

59. Hong J, Buddenkotte J, Berger TG, Steinhoff M. Management of itch in atopic dermatitis. Semin Cutan Med Surg. 2011;30:71-86.

60. Bieber T. Atopic dermatitis. N Engl J Med. 2008;358:1483-94.

61. Waldman AR, Ahluwalia J, Udkoff J, Borok JF, Eichenfield LF. Atopic Dermatitis. Pediatr Rev. 2018;39:180-93.

62. Lönndahl L, Holst M, Bradley M, Killasli H, Heilborn J, Hall MA, et al. Substance $\mathrm{P}$ antagonist aprepitant shows no additive effect compared with standardized topical treatment alone in patients with atopic dermatitis. Acta Derm Venereol. 2018;98:324-8.

63. Lönndahl L, Rasul A, Lonne-Rahm S-B, Holst M, Johansson B, El-Nour H, et al. Tachykinin upregulation in atopic dermatitis. Immunopharmacol Immunotoxicol. 2019;41:117-22.

64. Frenkl TL, Zhu H, Reiss T, Seltzer O, Rosenberg E, Green S. A multicenter, double-blind, randomized, placebo controlled trial of a neurokinin-1 receptor antagonist for overactive bladder. J Urol. 2010;184:616-22.

65. Yosipovitch G, Ständer S, Kerby MB, Larrick JW, Perlman AJ, Schnipper EF, et al. Serlopitant for the treatment of chronic pruritus: Results of a randomized, multicenter, placebo-controlled phase 2 clinical trial. J Am Acad Dermatol. 2018;78(882-891):e10.

66. Ständer S, Kwon P, Hirman J, Perlman AJ, Weisshaar E, Metz $\mathrm{M}$, et al. Serlopitant reduced pruritus in patients with prurigo nodularis in a phase 2, randomized, placebo-controlled trial. J Am Acad Dermatol. 2019;80:1395-402.

67. Pariser DM, Bagel J, Lebwohl M, Yosipovitch G, Chien E, Spellman MC. Serlopitant for psoriatic pruritus: a phase 2 randomized, double-blind, placebo-controlled clinical trial. J Am Acad Dermatol. 2020;82:1314-20.

68. Study of the Efficacy, Safety and Tolerability of Serlopitant for the Treatment of Pruritus (Itch) With Prurigo Nodularis [Internet]. 
https://clinicaltrials.gov/ct2/show/NCT03546816. Accessed 22 Dec 2020.

69. Study of the Efficacy, Safety and Tolerability of Serlopitant for the Treatment of Pruritus (Itch) With Prurigo Nodularis [Internet]. https://clinicaltrials.gov/ct2/show/record/NCT0367740 1?view=record. Accessed 11 Jan 2021.

70. Papanikolaou M, Onoufriadis A, Mellerio JE, Nattkemper L, Yosipovitch G, Steinhoff M, et al. Prevalence, pathophysiology and management of itch in epidermolysis bullosa. Br J Dermatol. 2020. https://doi.org/10.1111/bjd.19496.

71. Chiou AS, Choi S, Barriga M, Dutt-Singkh Y, Solis DC, Nazaroff $\mathrm{J}$, et al. Phase 2 trial of a neurokinin-1 receptor antagonist for the treatment of chronic itch in patients with epidermolysis bullosa: a randomized clinical trial. J Am Acad Dermatol. 2020;82:1415-21.

72. A Neurokinin-1 Receptor Antagonist for the Treatment of Pruritus in Patients With Epidermolysis Bullosa [Internet]. https://clini caltrials.gov/ct2/show/NCT03836001. Accessed 07 Sept 2020.

73. American Academy of Dermatology (AAD) 2018 Annual Meeting. Heitman A, Xiao C, Cho Y, Polymeropoulos C, Birznieks G, Polymeropoulous M. Tradipitant improves worst itch and disease severity in patients with chronic pruritus related to atopic dermatitis. Accessed 19 Aug 2020.

74. Vanda Reports results from the EPIONE study of Tradipitant in the treatment of Pruritus in Atopic Dermatitis. 2020. https://vanda pharmaceuticalsinc.gcs-web.com/node/13961/pdf. Accessed 19 Aug 2020.
75. Di Fabio R, Alvaro G, Braggio S, Carletti R, Gerrard PA, Griffante $\mathrm{C}$, et al. Identification, biological characterization and pharmacophoric analysis of a new potent and selective NK1 receptor antagonist clinical candidate. Bioorg Med Chem. 2013;21:6264-73.

76. Ratti E, Bettica P, Alexander R, Archer G, Carpenter D, Evoniuk $\mathrm{G}$, et al. Full central neurokinin-1 receptor blockade is required for efficacy in depression: evidence from orvepitant clinical studies. J Psychopharmacol (Oxford). 2013;27:424-34.

77. Trower MK, Fisher A, Upton N, Ratti E. Neurokinin-1 receptor antagonist orvepitant is an effective inhibitor of itch-associated response in a Mongolian gerbil model of scratching behaviour. Exp Dermatol. 2014;23:858-60.

78. Vincenzi B, Trower M, Duggal A, Guglielmini P, Harris P, Jackson D, et al. Neurokinin-1 antagonist orvepitant for EGFRIinduced pruritus in patients with cancer: a randomised, placebocontrolled phase II trial. BMJ Open. 2020;10:e030114.

79. Pojawa-Gołąb M, Jaworecka K, Reich A. NK-1 receptor antagonists and pruritus: review of current literature. Dermatol Ther (Heidelb). 2019;9:391-405.

80. Azimi E, Reddy VB, Shade K-TC, Anthony RM, Talbot S, Pereira PJS, et al. Dual action of neurokinin-1 antagonists on Mas-related GPCRs. JCI Insight. 2016;1:362.

81. Chen S, Lu M, Liu D, Yang L, Yi C, Ma L, et al. Human substance $\mathrm{P}$ receptor binding mode of the antagonist drug aprepitant by NMR and crystallography. Nat Commun. 2019;10:638. 